\title{
How to write a review article?
}

\author{
Ömer Gülpınar, Adil Güçal Güçlü
}

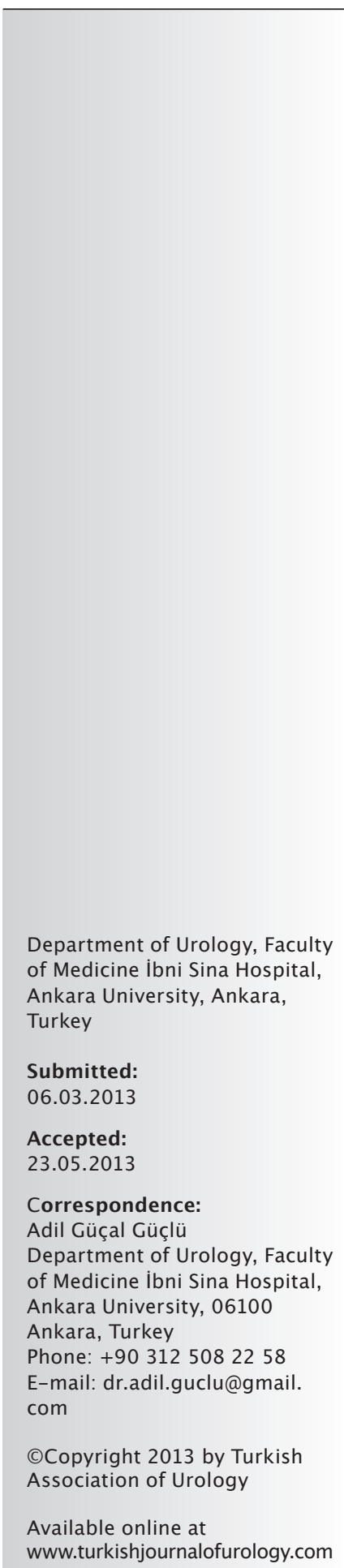

\begin{abstract}
In the medical sciences, the importance of review articles is rising. When clinicians want to update their knowledge and generate guidelines about a topic, they frequently use reviews as a starting point. The value of a review is associated with what has been done, what has been found and how these findings are presented. Before asking 'how,' the question of 'why' is more important when starting to write a review. The main and fundamental purpose of writing a review is to create a readable synthesis of the best resources available in the literature for an important research question or a current area of research. Although the idea of writing a review is attractive, it is important to spend time identifying the important questions. Good review methods are critical because they provide an unbiased point of view for the reader regarding the current literature. There is a consensus that a review should be written in a systematic fashion, a notion that is usually followed. In a systematic review with a focused question, the research methods must be clearly described. A 'methodological filter' is the best method for identifying the best working style for a research question, and this method reduces the workload when surveying the literature. An essential part of the review process is differentiating good research from bad and leaning on the results of the better studies. The ideal way to synthesize studies is to perform a meta-analysis. In conclusion, when writing a review, it is best to clearly focus on fixed ideas, to use a procedural and critical approach to the literature and to express your findings in an attractive way.
\end{abstract}

Key words: How to write; review; writing.

The importance of review articles in health sciences is increasing day by day. Clinicians frequently benefit from review articles to update their knowledge in their field of specialization, and use these articles as a starting point for formulating guidelines. ${ }^{[1,2]}$ The institutions which provide financial support for further investigations resort to these reviews to reveal the need for these researches. ${ }^{[3]}$ As is the case with all other researches, the value of a review article is related to what is achieved, what is found, and the way of communicating this information. A few studies have evaluated the quality of review articles. Murlow evaluated 50 review articles published in 1985, and 1986, and revealed that none of them had complied with clear-cut scientific criteria. ${ }^{[4]}$ In 1996 an international group that analyzed articles, demonstrated the aspects of review articles, and meta-analyses that had not complied with scientific criteria, and elaborated QUOROM (QUality Of Reporting Of Meta-analyses) statement which focused on meta-analyses of randomized controlled studies ${ }^{[5]}$ Later on this guideline was updated, and named as PRISMA (Preferred Reporting Items for Systematic Reviews and Meta-Analyses). ${ }^{[6]}$

Review articles are divided into 2 categories as narrative, and systematic reviews. Narrative reviews are written in an easily readable format, and allow consideration of the subject matter within a large spectrum. However in a systematic review, a very detailed, and comprehensive literature surveying is performed on the selected topic. ${ }^{[7,8]}$ Since it is a result of a more detailed literature surveying with relatively lesser involvement of author's bias, systematic reviews are considered as gold standard articles. Systematic reviews can be diivded into qualitative, and quantitative reviews. In both of them detailed literature surveying is performed. However in quantitative reviews, study data are collected, and statistically evaluated (ie. meta-analysis). ${ }^{[8]}$

Before inquring for the method of preparation of a review article, it is more logical to 
investigate the motivation behind writing the review article in question. The fundamental rationale of writing a review article is to make a readable synthesis of the best literature sources on an important research inquiry or a topic. This simple definition of a review article contains the following key elements:

1. The question(s) to be dealt with

2. Methods used to find out, and select the best quality researches so as to respond to these questions.

3. To synthetize available, but quite different researches

For the specification of important questions to be answered, number of literature references to be consulted should be more or less determined. Discussions should be conducted with colleagues in the same area of interest, and time should be reserved for the solution of the problem(s). Though starting to write the review article promptly seems to be very alluring, the time you spend for the determination of important issues won't be a waste of time..$^{[9]}$

The PRISMA statement ${ }^{[6]}$ elaborated to write a well-designed review articles contains a 27 -item checklist (Table 1). It will be reasonable to fulfill the requirements of these items during preparation of a review article or a meta-analysis. Thus preparation of a comprehensible article with a high-quality scientific content can be feasible.

\section{Contents and format}

Important differences exist between systematic, and nonsystematic reviews which especially arise from methodologies used in the description of the literature sources. A non-systematic review means use of articles collected for years with the recommendations of your colleagues, while systematic review is based on struggles to search for, and find the best possible researches which will respond to the questions predetermined at the start of the review.

Though a consensus has been reached about the systematic design of the review articles, studies revealed that most of them had not been written in a systematic format. McAlister et al. analyzed review articles in 6 medical journals, and disclosed that in less than one fourth of the review articles, methods of description, evaluation or synthesis of evidence had been provided, one third of them had focused on a clinical topic, and only half of them had provided quantitative data about the extend of the potential benefits. ${ }^{[10]}$

Use of proper methodologies in review articles is important in that readers assume an objective attitude towards updated information. We can confront two problems while we are using data from researches in order to answer certain questions. Firstly, we can be prejudiced during selection of research articles or these articles might be biased. To

\section{Table 1. PRISMA statement: A 27-item checklist}

Title

Title

Summary

Structured

summary

Introduction

Rationale

Objectives
1 Identify the article as a systematic review, meta-analysis, or both

2 Write a structured summary including, as applicable, background; objectives; data sources; study eligibility criteria, participants, treatments, study appraisal and synthesis methods; results; limitations; conclusions and implications of key findings; and systematic review registration number

3 Explain the rationale for the review in the context of what is already known

4 Provide an explicit statement of questions being addressed with reference to participants, interventions, comparisons, outcomes, and study design (PICOS)

Methods

Protocol and registration

5 Indicate if a review protocol exists, if and where it can be accessed (such as a web address), and, if available, provide registration information including the registration number

Eligibility criteria

6 Specify study characteristics (such as PICOS, length of follow-up) and report characteristics (such as years considered, language, publication status) used as criteria for eligibility, giving rationale

Sources of Information

7 Describe all information sources in the survey (such as databases with dates of coverage, contact with study authors to identify additional studies) and date last searched

Survey

8 Present the full electronic search strategy for at least one major database, including any limits used, such that it could be repeated

Study selection
9 State the process for selecting studies (that is, for screening, for determining eligibility, for inclusion in the systematic review, and, if applicable, for inclusion in the meta-analysis) 


\begin{tabular}{|c|c|c|}
\hline $\begin{array}{l}\text { Data collection } \\
\text { process }\end{array}$ & 10 & $\begin{array}{l}\text { Describe the method of data extraction from reports (such as piloted forms, independently by two reviewers) } \\
\text { and any processes for obtaining and confirming data from investigators }\end{array}$ \\
\hline Data items & 11 & $\begin{array}{l}\text { List and define all variables for which data were sought (such as PICOS, funding sources) and any assumpti- } \\
\text { ons and simplifications made }\end{array}$ \\
\hline $\begin{array}{l}\text { Risk of bias } \\
\text { in individual } \\
\text { studies }\end{array}$ & 12 & $\begin{array}{l}\text { Describe methods used for assessing risk of bias in individual studies (including specification of whether this } \\
\text { was done at the study or outcome level, or both), and how this information is to be used in any data synthesis }\end{array}$ \\
\hline Summary measures & 13 & State the principal summary measures (such as risk ratio, difference in means) \\
\hline $\begin{array}{l}\text { Synthesis of } \\
\text { outcomes }\end{array}$ & 14 & $\begin{array}{l}\text { For each meta-analysis, explain methods of data use, and combination methods of study outcomes, and if } \\
\text { done consistency measurements should be indicated (ie P test) }\end{array}$ \\
\hline $\begin{array}{l}\text { Risk of bias } \\
\text { across studies }\end{array}$ & 15 & $\begin{array}{l}\text { Specify any assessment of risk of bias that may affect the cumulative evidence (such as publication } \\
\text { bias, selective reporting within studies). }\end{array}$ \\
\hline Additional analyses & 16 & $\begin{array}{l}\text { Describe methods of additional analyses (such as sensitivity or subgroup analyses, meta-regression), if done, } \\
\text { indicating which were pre-specified. }\end{array}$ \\
\hline \multicolumn{3}{|l|}{ Results } \\
\hline Study selection & 17 & $\begin{array}{l}\text { Give numbers of studies screened, assessed for eligibility, and included in the review, with reasons for exclusi- } \\
\text { ons at each stage, ideally with a flow diagram. }\end{array}$ \\
\hline \multicolumn{2}{|c|}{ Study characteristics 18} & $\begin{array}{l}\text { For each study, present characteristics for which data were extracted (such as study size, PICOS, follow-up } \\
\text { period) and provide the citation. }\end{array}$ \\
\hline $\begin{array}{l}\text { Risk of bias } \\
\text { within studies }\end{array}$ & 19 & Present data on risk of bias of each study and, if available, any outcome-level assessment (see item 12) \\
\hline $\begin{array}{l}\text { Results of } \\
\text { individual studies }\end{array}$ & 20 & $\begin{array}{l}\text { For all outcomes considered (benefits and harms), present, for each study, simple summary data for each } \\
\text { intervention group and effect estimates and confidence intervals, ideally with a forest plot (a type of graph } \\
\text { used in meta-analyses which demonstrates relat,ve success rates of treatment outcomes of multiple scientific } \\
\text { studies analyzing the same topic) }\end{array}$ \\
\hline Syntheses of resxults & 21 & Present the results of each meta-analyses including confidence intervals and measures of consistency \\
\hline $\begin{array}{l}\text { Risk of bias } \\
\text { across studies }\end{array}$ & 22 & Present results of any assessment of risk of bias across studies (see item 15). \\
\hline Additional analyses & 23 & $\begin{array}{l}\text { Give results of additional analyses, if done such as sensitivity or subgroup analyses, meta-regression } \\
\text { (see item 16) }\end{array}$ \\
\hline \multicolumn{3}{|l|}{ Discussion } \\
\hline $\begin{array}{l}\text { Summary of } \\
\text { evidence }\end{array}$ & 24 & $\begin{array}{l}\text { Summarize the main findings, including the strength of evidence for each main outcome; consider their } \\
\text { relevance to key groups (such as healthcare providers, users, and policy makers) }\end{array}$ \\
\hline Limitations & 25 & $\begin{array}{l}\text { Discuss limitations at study and outcome level (such as risk of bias), and at review level such as incomplete } \\
\text { retrieval of identified research, reporting bias }\end{array}$ \\
\hline Conclusions & 26 & $\begin{array}{l}\text { Provide a general interpretation of the results in the context of other evidence, and implications for future } \\
\text { research }\end{array}$ \\
\hline \multicolumn{3}{|l|}{ Funding } \\
\hline Funding & 27 & $\begin{array}{l}\text { Indicate sources of funding or other support (such as supply of data) for the systematic review, and the role of } \\
\text { funders for the systematic review }\end{array}$ \\
\hline
\end{tabular}

minimize this risk, methodologies used in our reviews should allow us to define, and use researches with minimal degree of bias. The second problem is that, most of the researches have been performed with small sample sizes. In statistical methods in meta-analyses, available researches are combined to increase the statistical power of the study. The problematic aspect of a non-systematic review is that our tendency to give biased responses to the questions, in other words we apt to select the studies with known or favourite results, rather than the best quality investigations among them.

As is the case with many research articles, general format of a systematic review on a single subject includes sections of Introduction, Methods, Results, and Discussion (Table 2). 


\section{Preparation of the review article}

Steps, and targets of constructing a good review article are listed in Table 3. To write a good review article the items in Table 3 should be implemented step by step. ${ }^{[1-13]}$

\section{The research question}

It might be helpful to divide the research question into components. The most prevalently used format for questions related to the treatment is PICO (P - Patient, Problem or Population; I-Intervention; C-appropriate Comparisons, and O-Outcome measures) procedure. For example In female patients $(\mathrm{P})$ with stress urinary incontinence, comparisons $(\mathrm{C})$ between transobturator, and retropubic midurethral tension-free band surgery (I) as for patients' satisfaction $(\mathrm{O})$.

\section{Finding Studies}

In a systematic review on a focused question, methods of investigation used should be clearly specified.

Ideally, research methods, investigated databases, and key words should be described in the final report. Different databases are used dependent on the topic analyzed. In most of the clinical topics, Medline should be surveyed. However searching through Embase and CINAHL can be also appropriate.

While determining appropriate terms for surveying, PICO elements of the issue to be sought may guide the process. Since in general we are interested in more than one outcome, $\mathrm{P}$, and I can be key elements. In this case we should think about synonyms of $\mathrm{P}$, and I elements, and combine them with a conjunction AND.

One method which might alleviate the workload of surveying process is "methodological filter" which aims to find the best investigation method for each research question. A good example of this method can be found in PubMed interface of Medline. The Clinical Queries tool offers empirically developed filters for five different inquiries as

\begin{tabular}{|c|c|}
\hline Section & Contents \\
\hline Introduction & $\begin{array}{l}\text { Presents the problem and certain issues dealt in the } \\
\text { review article }\end{array}$ \\
\hline \multirow[t]{2}{*}{ Methods } & Describes research, and evaluation process \\
\hline & $\begin{array}{l}\text { Specifies the number of studies evaluated or } \\
\text { selected }\end{array}$ \\
\hline Results & Describes the quality, and outcomes of the selected studies \\
\hline Discussion & $\begin{array}{l}\text { Summarizes results, limitations, and outcomes of the } \\
\text { procedure and research }\end{array}$ \\
\hline
\end{tabular}

guidelines for etiology, diagnosis, treatment, prognosis or clinical prediction.

\section{Evaluation of the Quality of the Study}

As an indispensable component of the review process is to discriminate good, and bad quality researches from each other, and the outcomes should be based on better qualified researches, as far as possible. To achieve this goal you should know the best possible evidence for each type of question The first component of the quality is its general planning/design of the study. General planning/design of a cohort study, a case series or normal study demonstrates variations.

A hierarchy of evidence for different research questions is presented in Table 4. However this hierarchy is only a first step. After you find good quality research articles, you won't need to read all the rest of other articles which saves you tons of time. ${ }^{[14]}$

\section{Formulating a Synthesis}

Rarely all researches arrive at the same conclusion. In this case a solution should be found. However it is risky to make a decision based on the votes of absolute majority. Indeed, a well-performed large scale study, and a weakly designed one are weighed on the same scale. Therefore, ideally a meta-analysis should be performed to solve apparent differences. Ideally, first of all, one should be focused on the largest, and higher quality study, then other studies should be compared with this basic study.

\section{Conclusions}

In conclusion, during writing process of a review article, the procedures to be achieved can be indicated as follows: 1) Get rid of fixed ideas, and obsessions from your head, and view the subject from a large perspective. 2) Research articles in the literature should be approached with a methodological, and critical attitude and 3) finally data should be explained in an attractive way.

\section{Table 3. Steps of a systematic review}

\begin{tabular}{|ll}
\hline Step & Processes \\
$\begin{array}{l}\text { Formulation of researchable } \\
\text { questions }\end{array}$ & Select answerable questions \\
\hline Disclosure of studies & $\begin{array}{l}\text { Databases, and } \\
\text { key words }\end{array}$ \\
\hline Evaluation of its quality & $\begin{array}{l}\text { Quality criteria during selection } \\
\text { of studies }\end{array}$ \\
\hline Synthesis & $\begin{array}{l}\text { Methods interpretation, and } \\
\text { synthesis of outcomes }\end{array}$ \\
\hline
\end{tabular}




\section{Table 4. Determination of levels of evidence based on the type of the research question}

\begin{tabular}{|c|c|c|c|c|}
\hline Level & Intervention & Diagnosis & Prognosis & Etiology \\
\hline I & $\begin{array}{l}\text { Systematic review } \\
\text { of Level II studies }\end{array}$ & $\begin{array}{l}\text { Systematic review of } \\
\text { Level II studies }\end{array}$ & $\begin{array}{l}\text { Systematic review of } \\
\text { Level II studies }\end{array}$ & $\begin{array}{l}\text { Systematic review } \\
\text { of Level II studies }\end{array}$ \\
\hline II & Randomized controlled study & $\begin{array}{l}\text { Crross-sectional study } \\
\text { in consecutive patients }\end{array}$ & Initial cohort study & Prospective cohort study \\
\hline III & $\begin{array}{l}\text { One of the following: Non-randomized } \\
\text { experimental study (ie. controlled pre-, and } \\
\text { post-test intervention study) Comparative } \\
\text { studies with concurrent control groups } \\
\text { (observational study) (ie. cohort study, } \\
\text { case-control study) }\end{array}$ & $\begin{array}{l}\text { One of the following: } \\
\text { Cross-sectional study in } \\
\text { non-consecutive case } \\
\text { series; diagnostic } \\
\text { case-control study }\end{array}$ & $\begin{array}{l}\text { One of the following: } \\
\text { Untreated control group } \\
\text { patients in a randomized } \\
\text { controlled study, integrated } \\
\text { cohort study }\end{array}$ & $\begin{array}{l}\text { One of the following: } \\
\text { Retrospective cohort study, } \\
\text { case-control study (Note: these } \\
\text { are most prevalently used } \\
\text { types of etiological studies; for } \\
\text { other alternatives, and } \\
\text { interventional studies see Level III }\end{array}$ \\
\hline IV & Case series & Case series & $\begin{array}{l}\text { Case series or cohort studies } \\
\text { with patients at different } \\
\text { stages of their disease states }\end{array}$ & \\
\hline
\end{tabular}

\section{References}

1. Oxman AD, Cook DJ, Guyatt GH. Users' guides to the medical 1 literature. VI. How to use an overview. Evidence-Based Medicine Working Group. JAMA 1994;272:1367-71.

2. Swingler GH, Volmink J, Ioannidis JP. Number of published systematic 2 reviews and global burden of disease: database analysis. BMJ 2003;327:1083-4.

3. Canadian Institutes of Health Research. Randomized controlled trials 3 registration/application checklist (12/2006). 2006. www.cihrirsc.gc.ca/e/documents/rct_reg_e.pdf (accessed 19 May 2009).

4. Mulrow $\mathrm{CD}$. The medical review article: state of the science. Ann Intern Med 1987;106:485-8.

5. Moher D, Cook DJ, Eastwood S, Olkin I, Rennie D, Stroup DF. Improving the quality of reports of meta-analyses of randomised controlled trials: the QUOROM statement. Quality of Reporting of Meta-analyses. Lancet 1999;354:1896-900.

6. Moher D, Liberati A, Tetzlaff J, Altman DG; PRISMA Group. Preferred reporting items for systematic reviews and meta-analyses: the PRISMA statement. BMJ 2009;339:b2535.

7. Collins JA, Fauser B. Balancing the strengths of systematicand narrative reviews. Hum Reprod Update 2005;11:103-4.
8. Green BN, Johnson CD, Adams A. Writing narrative literaturereviews for peer-reviewed journals: secrets of the trade. J SportsChiropract Rehabil 2001;15:5-19.

9. Booth, WC,Colomb GG, Williams JM. The craft of research, 2nd edn. 2003 Series : Chicago Guides to Writing, Editing and Publishing, Chicago: The Universty of Chicago Press, 2003.

10. McAlister FA, Clark HD, van Walraven C, Straus SE, Lawson FM, Moher D, et al. The medical review article revisited: has the science improved? Ann Intern Med 1999;131:947-51.

11. Glasziou P, Irwig P, Bain C, Colditz G. Systematic reviews in health care: a practical guide. Cambridge University Press 2001.

12. Khan KS, Kunz R, Kleijnen J, Antes G. Systematic reviews to support evidence based medicine. How to review and apply finding of health care research London: RSM Press 2003.

13. Mulrow C, Cook D, eds. Systematic reviews: synthesis of best evidence for health care decisions. Philadelphia: American Collage of Phtsicians 1998.

14. Glasziou PP, Vandenbroucke J, Chalmers I. Assessing the quality of research. BMJ 2004;328:39-41. 